\title{
Mobile Payment: The Hiding Impact of Learning Costs on User Intentions
}

\section{Francisco-Jose Molina-Castillo', Carolina Lopez-Nicolas² and Mark de Reuver ${ }^{3}$}

${ }^{1}$ University of Murcia, Departamento de Comercialización e Investigación de Mercados, Murcia, Spain, fjmolina@um.es

2 University of Murcia, Departamento de Organización de Empresas y Finanzas, Murcia, Spain, carlopez@um.es

${ }^{3}$ Delft University of Technology, Faculty Technology, Policy and Management, Delft, The Netherlands, G.A.deReuver@tudelft.nl

Received 6 July 2018; received in revised form 8 October 2018; accepted 7 January 2019

\begin{abstract}
This study analyzes how learning costs for technologies that lack de facto standards, such as mobile payment, affect user intentions. In addition, we evaluate how the negative effect of learning costs is mediated by perceived functional value and facilitating conditions. Data used in this research was obtained from a study among 463 consumers. We find support that negative effects from learning costs are fully mediated by perceived functional value and facilitating conditions. Hence, one important reason of slow user acceptance is that the high diversity mobile payment services, platforms and technologies increases the learning costs of users. The results pose important implications for managers willing to increase the acceptance of mobile payment.
\end{abstract}

Keywords: Mobile payment, Perceived functional value, Facilitating conditions, Learning costs, Intention to use 


\section{Introduction}

The acceptance of mobile payments has gained attention by academics and practitioners in the last decade [7], [44], [70]. Apple Pay, Google Wallet and PayPal are only some examples of technologies to go shopping using the mobile phone [54]. Also, retailers have become aware of the need to explore mobile payment [59] due to the impact that this technology could have on purchase intention [72]. All mobile payment technologies share a common characteristic: they allow payments for services and goods using mobile phones [2]. Nonetheless, very few of these mobile payment solutions have achieved success in the market or reached a critical mass of users [55].

Mobile payment was first defined as the use of a mobile device to conduct a payment transaction in which money or funds are transferred from payer to receiver, either via an intermediary or directly [37]. Putting that simpler, mobile payment allows users to pay for the goods or services through mobile phones [46]. The attention to mobile payment has increased substantially in the past years due to the advance in the infrastructure, government regulations and new mobile devices capable of handling them [6]. In addition, societal, economic and efficiency gains have been proposed from replacing cash-based payments with mobile payments, which in turn might drive innovative business models [58].

The high variety of coexisting mobile payment technologies and solutions without de facto standards has created high complexity in the market [28]. Mobile payment solutions are offered in highly diverse ways: by mobile phone operators using the SIM card in the phone, handset manufacturers using chips soldered on the phone motherboard and over-the-top providers using emulation in the cloud [13]. Users face a high variety of mobile payment services with different interface standards: some of them differ regarding which hardware is needed (e.g. a specific SIM card, phone motherboard or cloud connectivity) while others differ on how to access the service (e.g. downloadable app from an app store or extensible wallet application). The diversity of solutions leads to confusion of consumers [8]. Users also face confusion with a different number of user interface standards: some of these mobile payments need to authenticate and authorize payments (e.g. through entering PIN codes, automatically downloading tokens or using body functions like fingerprint or even blood circulation patterns), while others do not make clear the service and what kind of functionality to expect (e.g. payment only or added-value features like loyalty cards and electronic receipts). Following this argument, other authors have described the user interface limitations of some platforms such as PayPal [32].

In addition, many mobile payment solutions are drastically altered after their market introduction or even removed completely from the market. In short, de facto standards for the user interface, user interaction, security mechanisms, distribution channels and functionality are all lacking in the market, and it is yet unclear which solutions will be winning in the long-run. Hence, users face learning costs while adopting different offerings in the market. These learning costs negatively affect the value that users expect from mobile payment [43].

Recent streams on mobile payment recommend analyzing several factors simultaneously that might impact user's intention to use mobile payment [11]. In order to do so, it is important to consider the advantages and drawbacks that mobile payment could bring to users [49]. The present study analyses the impact that perceived functional value and facilitating conditions could have on user's intention to use mobile payment, as well as the drawback that learning costs might have in this user's intention to use mobile payment. Specifically, in this way, we examine whether learning costs have a hidden impact on user's intentions, mediated by perceived functional value and facilitating conditions.

The remainder of this paper is organized as follows. The next section analyses the conceptual background around mobile payments from the different contributions in extant literature. Following, we propose the hypotheses of our study. Then, we discuss the methodology to test our proposed model. Finally, the results obtained are discussed and the managerial contributions are highlighted.

\section{Conceptual Background and Hypotheses}

In this section we describe the theoretical contributions in the field of mobile payment in order to highlight the gaps in the literature. Also, we present the main concepts and expected links behind the suggested hypotheses to be tested in the research model.

\subsection{Mobile Payment}

Mobile payment is considered a revolutionary technology that transforms consumer buying processes as well as business models of providers. Several authors such as Au and Kauffman [2] and Kousaridas, et al. [29] agree on the idea that mobile payment involves buying goods or services by using a mobile device inside a mobile communication platform. Therefore, two main elements constitute the definition of mobile payment: 1) the mobile technology or service to conduct the payment and 2) the network or platform needed for the payment to take place. 
With regard to the first element, several technologies for mobile payment can be used. For example, Zhou [73] underline that mobile phones are the tool to conduct mobile payment, whereas Dewan and Chen [15] extend the domain to include personal digital assistants (PDA) or radio frequency (RF) devices. Cheng and Chang [8] pay attention to the potential benefits of NFC technology. In addition, mobile payment studies have been applied to several domains: mobile ticketing [37], mobile Internet payments [38], and mobile payment tools in Virtual Social Networks [32].

The second element that defines mobile payment is related to the platform or network through which the payment takes place. Pousttchi [46] state that in order to initiate, authorize, or complete the payment, mobile devices should be used in conjunction with mobile communication techniques. Therefore, as stated by Dahlberg, et al. [12], firms must take advantage of wireless and other communication technologies. Miao and Jayakar [39] explain that different mobile platforms coexist in the market, offered by (1) mobile network operators, (2) banks (or financial institutions), (3) third-party platforms, and (4) hybrid models from strategic alliances of banks and mobile operators. These platforms coexist as there are several options for where to position the secure element that authenticates mobile payment users: in the SIM card of the device, on the motherboard of the device or in a cloud emulator [13]. Consequently, players like mobile network operators, device manufacturers, banks, card schemes and over-the-top providers are all offering alternative solutions for mobile payment, and struggle to come up with joint solutions [41]. There are several examples of these suggested platforms in the market, and some providers have created their own mobile payment platform, becoming independent from financial institutions [4].

In summary, as explained by Pousttchi [46], these interdependent factors (technical, human and market) should be combined adequately in order to be successful in any mobile payment process. For example, [22] argues that, based on technical factors, limited availability of NFC initially slowed down the adoption process of mobile payment. In this paper, we combine multiple theories for analyzing the determining factors of intention to use mobile payments: value (perceived value approach), facilitating conditions (the Unified Theory of Acceptance and Use of Technology, UTAUT) and learning costs (in the broader discourse on switching costs).

\subsection{Perceived Functional Value of Mobile Payment}

The perceived value approach is rooted in the field of economics and utility theories. Perceived value is the consumer's overall assessment of the utility of a product/service based on perceptions of what is received and what is given [71]. Value has functional and emotional dimensions. Functional value refers to the utility resulting from quality perception and performance expectation, while emotional value is defined as the utility derived from feelings or affective states that a product generates [62]. [24] develop a Value-based adoption model of mobile Internet, in which emotional value is related to enjoyment and functional value relates to usefulness. Some disagreement exists in how perceived value should be proxied in the mobile literature. Three alternatives can be identified: as diverse individual dimensions [52], as a second-order construct made of several value components [10], or as a unidimensional concept [70]. Based on the different dimensions of perceived value, and the intercorrelations among the different dimensions of perceived value [57], this paper focuses on perceived functional value.

Perceived value of mobile payment services is relevant on its functional dimension. Mobile payment is an advanced mobile service mainly adopted for its multiple functionalities [23] [53] in the first place, not for its perceived enjoyment or emotional value. Like other mobile transaction services that are more functional and less categorized as mobile entertainment [25], mobile payment is considered here to have functional rather than emotional value. Perceived value is closely related to consumer's evaluations of what she/he receives and sacrifices [42] and has traditionally been defined as the trade-off between benefits and costs, i.e. between what the user gets and gives when using a service [71]. Cost-benefit theory has also been applied to mobile payment research, although most studies only consider monetary perceived costs and risk [5]. In their pioneering paper on perceived value of mobile channel, [25] conclude that consumers focus more on the costs of the mobile channel than on its benefits. More recent conceptualizations of value support the idea that value is more than just a comparison between costs and benefits and acknowledges that value is situational and can change before, during, or after an experience [71]. Moreover, additional costs may arise when considering specific mobile services [35]. For mobile Internet, [24] propose technicality of the mobile service to be a cost facet of perceived value. That might be also the case for mobile payment services. Following prior research, the present paper adopts a cost-benefit approach and analyses learning costs (cognitive effort or non-monetary costs), facilitating conditions and perceived functional value of mobile payment.

Perceived functional value has been shown to have a positive effect on the behavioural intention to use a new technology, for instance regarding mobile location-based services [48], SMS [62], mobile internet [24], mobile payment [70], mobile channel [25], mobile coupons [34], and mobile services [52]. In a similar way, some studies have focused on the role of perceived functional value of a new mobile technology on explaining the intention to pay for it, purchase intention [20], commitment [48], word of mouth [20] or attitude toward those services. Mobile payment is a new technology for many people. It is crucial that users perceive a positive overall evaluation to be motivated to use this and more importantly to balance the set of features and functionalities [55]. In line with above discussion, we posit that perceived functional value of mobile payment might have a positive influence on the user's intention to use it: 
H1: Perceived functional value has a positive effect on the behavioural intention to use mobile payment services.

\subsection{Facilitating Conditions of Mobile Payment}

Facilitating conditions are defined as "the degree to which an individual believes that an organizational and technical infrastructure exists to support use of the system" [63]. This concept is rooted in the Perceived Behavioural Control and Innovation diffusion theories and a major predictor of the acceptance of new technologies in the Unified Theory of Acceptance and Use of Technology (UTAUT) [63]. Prior research following cost-benefit theory sees facilitating conditions as a potential reducer of sacrifice component of perceived functional value [24] and a construct made of response cost and self-efficacy [56].

In the mobile context, the concept of facilitating conditions is seen as a very relevant determinant of mobile services use, thus playing an important role in the acceptance of mobile payment. Following UTAUT, most studies focus on the impact of facilitating conditions on actual use of a new technology [63]. Some recent articles, though, have modified UTAUT and started to analyse the direct effect of facilitating conditions on behavioural intention to use specific mobile services [60].

In the last decade, many studies have analysed the direct effect of facilitating conditions on intention to use specific mobile services. For instance, prior research on mobile payment has found a positive effect of facilitating conditions on mobile shopping [69], mobile advertising [40] and mobile TV [68]. In addition, facilitating conditions has been shown to have a positive effect on usefulness of mobile banking, performance expectations of mobile shopping [69] and wireless trust which in turn affects behavioural intention to use mobile Internet [35].

Specifically, we propose a positive influence of facilitating conditions on the intention to use mobile payment services. These facilitating conditions could be the support offered by payment providers for using services and the infrastructure to conduct mobile payments in practical situations such as points of sale. Such facilitating conditions are especially important given the multitude of standards, platforms, technologies and offerings on the market. When an individual believes that the needed infrastructure and support for using mobile payment services exists, he or she is more likely to use mobile payments, which in turn will influence the actual use of mobile payment services [61]. Accordingly, we propose the following hypothesis:

\section{H2: Facilitating conditions has a positive effect on the behavioural intention to use mobile payment services.}

\subsection{Learning Costs of Mobile Payment}

In marketing, management, and economics literature, a consensus has emerged that switching costs are prevalent in a wide variety of industrial and consumer contexts [26]. Switching costs are defined as the one-time costs that customers associate with the process of switching from one product to another [49]. While switching costs must be associated with the switching process, they need not be incurred immediately upon switching. Furthermore, switching costs need not be limited to objective, economic costs. When consumers simplistically state that it's just not worth it to switch providers, they may perceive impediments ranging from search costs, transaction costs, learning costs, loyalty-card discounts, customer habit, emotional cost and cognitive effort, coupled with financial, social, and psychological risk on the part of the buyer. Given their importance, it seems natural that firms would want to manage their customers' perceptions of switching costs

Switching costs have been decomposed in different types. [26] proposed three types of switching costs: transaction costs; learning costs; and artificial or contractual costs. In [21], six dimensions are identified: performance costs uncertainty costs; pre-switching search and evaluation costs; post-switching behavioural and cognitive costs; setup costs; and sunk costs. [5] categorizes procedural switching costs along four dimensions: economic risk costs; evaluation costs; set up costs; and learning costs. In the smartphone market, [43] analysed several categories of switching cots: searching costs; learning costs; artificial costs; sunk costs; and uncertainty costs. They found that searching, learning and uncertainty dimensions of switching costs are the most relevant in the smartphone market.

This paper focuses on Learning costs. This type of costs includes the time and effort needed to acquire, exchange and evaluate information [21]. Learning costs are considered transition costs that are incurred while shifting from one situation to a new situation, for example, learning to use a new information system [24]. Learning costs are nonmonetary perceived costs which include sacrifices (time, effort and search costs) needed to obtain or use a product or service [34]. The negative effect of learning cost on behavioural intention to use mobile payment services has been proposed and tested in few studies in the past. There is some evidence of a negative impact of learning costs on loyalty to SMS, similarly to the evidence obtained in other studies in this area [35].

Lee, et al. [30] found that absorptive capacity contributes to the intention to use mobile services. Reversely, the lack of prior knowledge requires potential users to learn how to use the new mobile payment service, thus incurring higher learning costs, higher switching costs and reducing their intention to use it. Similarly, [35] found that perceived costs had a significant negative effect on behavioural intention to use mobile payment services. There is evidence 
that switching costs have a significant impact on repeat choice behaviour [67]. Thus, if a critical mass of users is not reached, due to the learning costs required, mobile payment solutions will not be adopted [55].

Due to the special relevance of learning costs in the mobile context and the still low acceptance of mobile payment systems, the focus here is on studying the impact of learning costs on the acceptance of mobile payment services. Therefore, based on previous arguments, we propose the following hypothesis:

\section{H3: Learning costs has a negative effect on the behavioural intention to use mobile payment services.}

In prior research, perceived costs have been found to have no direct impact on intention to use mobile ticketing [37]. Also other studies found no significant effect when testing the direct path from learning costs to intention as specified in our H3 [31]. For this reason, we consider that the effect of learning costs on the intention to use mobile payment services may also be indirect and mediated by other concepts. Specifically, we focus on perceived functional value and facilitating conditions as factors that may play a role in the influence of learning costs on the intention to use mobile payments.

We suggest that perceived functional value can be influenced by learning costs. Higher perceived costs are expected to evoke lower value, although prior studies found no significant effect [66]. Conversely, in their study on mobile channel, [25] found that a greater cognitive effort reduces perceived functional value of the mobile channel and, in turn, the intention to use it. Based on previous arguments we propose that learning costs might have a negative impact on user's intention to use mobile payments through perceived functional value as the learning costs might reduce the overall perceived functional value of this technology. Therefore, we propose the following hypothesis:

H4: The negative influence of learning costs of mobile payments in intention to use mobile payment is mediated by perceived functional value of mobile payment.

Learning costs may reduce users' perceptions with regards to facilitating conditions available to use mobile payment services. Time, effort and search costs sacrifices hinder the perceptions and intentions toward using new systems. Indeed, cognitive effort, understood as an information search cost, has been found to be the strongest barrier to the use of the mobile channel [25]. In a study on mobile health services, [56] consider learning costs as part of response cost.

Thus, we propose that learning costs might impact negatively the infrastructure to support the system and in turn user intentions to use mobile payment. In the initial periods of a new mobile service, users incur evaluation costs (to gather information and assess that information before switching to the new service), and cognitive costs (to become familiar with the new service after switching). Those learning costs may reduce user perceptions of external conditions facilitating the acceptance and support of the new technology or mobile service. Prior research states that users require more effort and time to learn how to use mobile payment tools [60], thus incurring higher learning costs and having scarce time to spend on evaluating facilitating conditions available. Therefore, the presence of facilitating conditions is posited to increase user intentions to use mobile payments, while the existence of learning costs reduce user perceptions of facilitating conditions. Based on prior discussion, we posit the following:

H5: The negative influence of learning costs of mobile payments in intention to use mobile payment is mediated by facilitating conditions of mobile payment.

A theoretical model with proposed hypotheses is presented in Figure 1.

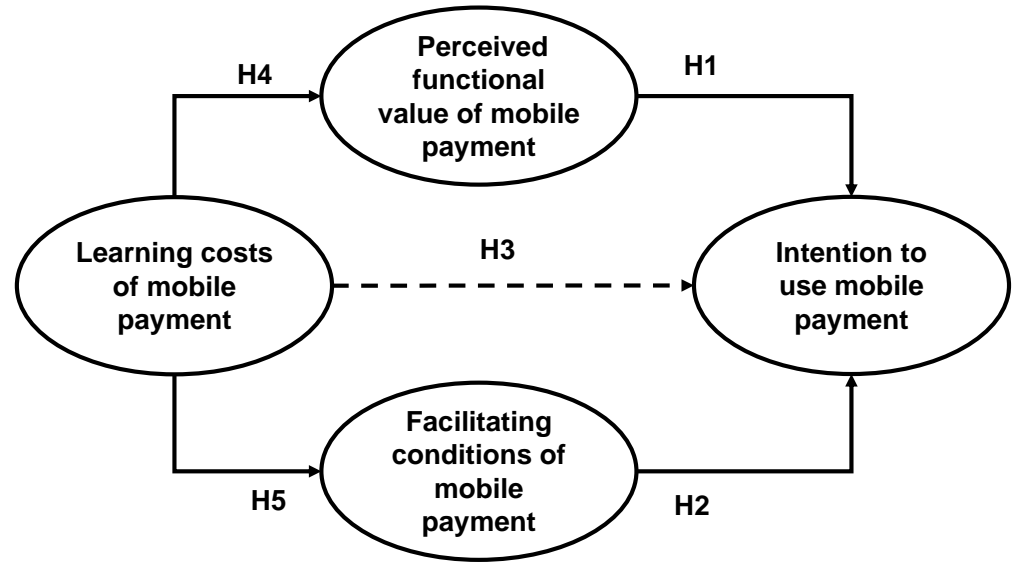

Figure 1: Theoretical model 


\section{Methodology}

In order to test the suggested hypotheses, we conducted a large quantitative study with university students. In this section, the research team describe the main steps in data collection as well as the tests conducted to check the reliability of the data.

\subsection{Data Collection}

Data used in this research was obtained from a study conducted in a major university. University students were considered as an appropriate sample due to their familiarity with the use of mobile phones and mobile services nowadays. They are frequently heavy users of mobiles devices and are aware of all the technological advances in this field. Moreover, recent studies demonstrate that these respondents are often willing to try new features on their mobile phones and pay for them [16].

A questionnaire was developed that self-administered through an online tool. All questions were tested with academic experts to improve readability and understanding. Also, a pre-test was conducted with respondents.

A total of 463 valid responses were obtained. $60 \%$ of our sample were men and $40 \%$ were women. The average time they spend with a mobile device over the day is between 2 and 5 hours. More than $70 \%$ of the students uses mainly a mobile phone, whereas $30 \%$ mainly uses other devices such as tablets. Over $55 \%$ of the students uses a credit card and $45 \%$ uses PayPal or similar technologies.

The measures used in this research were obtained from well-known tested scales, and are all measured on a Likert scale $(1-5)$ from totally disagree to totally agree. In order to measure perceived functional value we took into account recent contributions in [14]. The literature on switching costs is very prolific and we obtained our measures for learning costs from the work of Burnham, et al. [5] and also considered other contributions from Kohli [27]. This adaptation of the learning cost scale was confirmed in the pre-test as well as the reflective measures used. Facilitating conditions were extracted in [8]. Finally, Intention to use mobile payment was adapted from [37] [50] . A detailed list of scales is presented in Table 1.

Table 1: Measurement model

\begin{tabular}{|c|c|c|}
\hline Constructs and Items & SCR & Loadings \\
\hline \multicolumn{3}{|l|}{ Learning costs of mobile payment } \\
\hline LC1: Learning to use Mobile payment technology in my mobile device takes time & \multirow{3}{*}{.86} & .78 \\
\hline LC2: Getting used to Mobile payment technology in my mobile device takes time & & .95 \\
\hline $\begin{array}{l}\text { LC3: Even after some time it take effort to get up to speed to Mobile payment technology in } \\
\text { mobile device }\end{array}$ & & .70 \\
\hline \multicolumn{3}{|l|}{ Perceived functional value of mobile payment } \\
\hline PV1: Mobile payment technology in mobile device is reliable & \multirow{2}{*}{.73} & .77 \\
\hline PV2: Mobile payment technology in mobile device has good functions & & .74 \\
\hline \multicolumn{3}{|l|}{ Facilitating conditions of mobile payment } \\
\hline $\begin{array}{l}\text { FC1: I can easily access the relevant knowledge required for Mobile payment technology to } \\
\text { work in mobile device }\end{array}$ & \multirow[t]{2}{*}{.70} & .78 \\
\hline FC2: There are many practical situations in life in which a Mobile payment system may be used & & .65 \\
\hline \multicolumn{3}{|l|}{ Intention to use mobile payment } \\
\hline INT1: I will continue to use Mobile payment technology in mobile device in the future & \multirow{3}{*}{.85} & .82 \\
\hline INT2: My interest in using Mobile payment technology in mobile device will increase in the future & & .71 \\
\hline INT3: I will recommend using Mobile payment technology in mobile device & & .89 \\
\hline
\end{tabular}

\subsection{Reliability and Validity}

We conducted a confirmatory factor analysis (CFA) including the independent and dependent constructs with Lisrel 8.8. As can be observed in Table 1 , the results of the four-factor model suggest a good fit $\left(\chi^{2}(29)=78.08 ; C F I=.97\right.$, $\mathrm{NNFI}=.95, \mathrm{RMSEA}=.07$ ). Convergent validity was confirmed as all of the loadings for the items on their respective constructs were significant [3]. The reliability of the multi-item scales was assured by calculating the Bagozzi and Yi [3] composite reliability (SCR) and the average variance extracted (AVE) suggested by [17].

Two different approaches were used to test discriminant validity: 1) the correlation-AVE comparison [3] and 2) the heterotrait-monotrait (HTMT) ratio of discriminant validity. The first method is widely acknowledged in literature to 
test discriminant validity and compares the correlations of the constructs with the average variance extracted. However, a new stream of research suggests to include the heterotrait-monotrait (HTMT) ratio of discriminant validity [65] with a .85 cut-off point [19]. The HTMT test requires the calculation of a ratio of the average correlations between constructs and the geometric mean of the average correlations within items of the same constructs. The results of both approaches are reported in Table 2.

Table 2: Discriminant validity (AVE-Correlations and HTMT)

\begin{tabular}{|c|c|c|c|c|c|c|}
\hline \multicolumn{7}{|l|}{ AVE correlation comparison } \\
\hline & SCR & AVE & 1 & 2 & 3 & 4 \\
\hline 1. Learning costs & .86 & .67 & .82 & & & \\
\hline 2. Perceived functional value & .73 & .57 & $-.18^{* \star \star}$ & .75 & & \\
\hline 3.Facilitating conditions & .70 & .52 & $-.32^{\star \star \star}$ & $.54^{\star \star *}$ & .72 & \\
\hline 4.Intention to use & .85 & .66 & $-.26^{* \star *}$ & $.56^{\star * *}$ & $.52^{\star \star \star}$ & .81 \\
\hline \multicolumn{7}{|c|}{$\begin{array}{l}\text { SCR }=\text { Scale compose reliability, } A V E=\text { Average Variance Extracted } \\
\text { Elements in the main diagonal are the square root of the AVE } \\
\text { Levels of significance: }{ }^{* \star \star} p<.01\end{array}$} \\
\hline \multicolumn{7}{|c|}{ HTMT test } \\
\hline & & & 1 & 2 & 3 & 4 \\
\hline \multicolumn{7}{|l|}{ 1. Learning costs } \\
\hline 2. Perceived functional value & & & .06 & & & \\
\hline 3.Facilitating conditions & & & .58 & .44 & & \\
\hline 4.Intention to use & & & .51 & .54 & .62 & \\
\hline
\end{tabular}

Data was collected with a single step approach and from the same respondents. This could be an important threat in terms of common method variance (CMV) for our research [36]. To assess the potential risk of CMV, we conducted several distinct tests:

a. Harman one-factor test. if common method bias poses a serious threat to the analysis, a single latent factor would account for the majority of the covariance among the measures [45]. A Harman one factor tests showed that a single factor has a decidedly inferior fit compared to our multi factor structure.

b. As a further test, confirmatory factor analysis of the one-factor test [45] also revealed that a multi factor structure had a better fit in our model.

c. The Lindell and Whitney [33] marker variable technique also showed that common method bias was not problematic.

d. Finally, we used a latent method factor approach [45] that involves having all the items load on both their constructs and simultaneously in a common factor. This common factor did not improve the fit of our model.

\section{Results}

Results of the structural model show a satisfactory fit of the fit indices from Anderson and Gerbing [1] $\left(\chi^{2}(28)=\right.$ $122.41 ; \mathrm{CFI}=.95, \mathrm{NNFI}=.92, \mathrm{RMSEA}=.07)$. As can be observed in Figure 2, most of our hypotheses were confirmed. Perceived functional value has a positive impact on intention to use of mobile payments $(.42, p<.01)$. Similarly, facilitating conditions have a positive impact on intention to use mobile payments $(.59, p<.01)$. However, the direct negative impact of learning costs on intention to use mobile payment was not supported $(-.02, p>.10)$. Hence, the effect of Learning costs on Intention to use is indirect only, mediated through Perceived functional value and Facilitating conditions.

As our model includes multiple mediators, we used the recommendation in [47] to test multiple mediation constructs. The results show that perceived functional value and facilitating conditions fully mediate the impact of learning costs on intention to use mobile payment. An indirect negative effect of learning costs through perceived functional value on intention to use mobile payment was found $(-.10, \mathrm{p}<.01)$. In a similar manner, an indirect negative effect of learning costs through facilitating conditions on intention to use mobile payment was found $(-.17, p<.01)$.

The results of our research support that perceived functional value and facilitating conditions are two main antecedents of intention to use mobile payment. As a result, as Table 3 shows, both hypotheses $\mathrm{H} 1$ and $\mathrm{H} 2$ were supported. Accordingly, firms involved in mobile payments should take care of these two concepts if they want mobile payment to become a reality on a daily basis. 


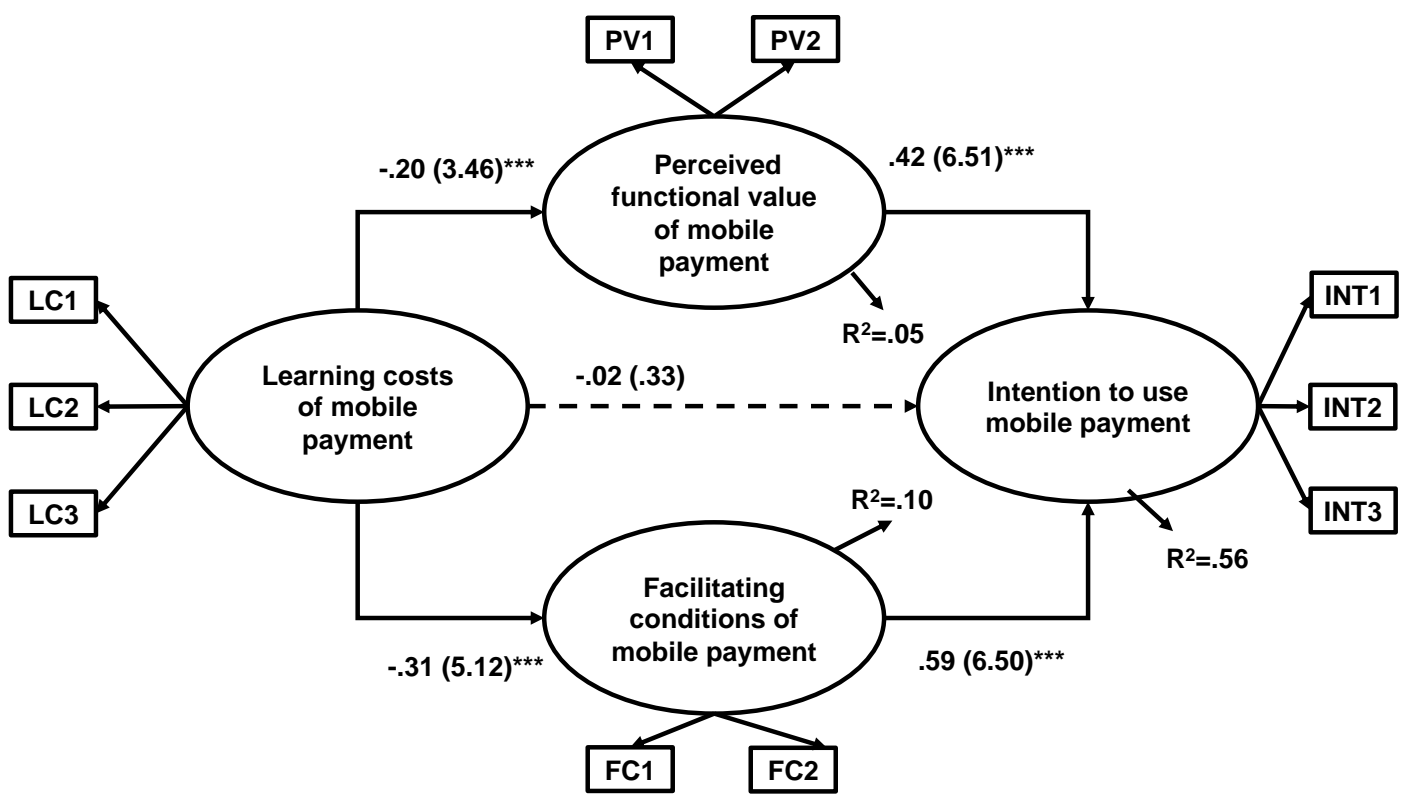

Figure 2: Structural model results

We found that hypothesis $\mathrm{H} 3$, suggesting a negative direct impact of learning cost, was not supported. Previous studies have also failed in supporting a negative impact of learning costs on behavioural intention to use mobile payment [37]. Nonetheless, our results show that the effect of learning costs on intention is not direct, but fully mediated by perceived functional value and facilitating conditions. In this regard, we have confirmed hypotheses $\mathrm{H} 4$ and $\mathrm{H} 5$ suggesting a negative indirect impact of learning costs on intention to use mobile payment through perceived functional value and facilitating conditions respectively.

Table 3: Summary of direct, indirect and total effects

\begin{tabular}{|l|l|l|l|l|}
\hline & Direct & Indirect & Total & Hypothesis \\
\hline $\begin{array}{l}\text { H1: Perceived functional value } \rightarrow \text { Intent. to use mobile } \\
\text { payment }\end{array}$ & $.42^{\star \star *}$ & n.a & $.42^{\star \star *}$ & Supported \\
\hline H2: Fac. Conditions $\rightarrow$ Intent. to use mobile payment & $.59^{\star \star *}$ & n.a & $.59^{\star \star *}$ & Supported \\
\hline H3: Learn. Costs $\rightarrow$ Intent. to use mobile payment (direct) & -.02 & n.a & -.02 & Not supported \\
\hline $\begin{array}{l}\text { H4: Learn. Costs } \rightarrow \text { Intent. to use mobile payment (indirect } \\
\text { through perceived functional value) }\end{array}$ & n.a & $-.10^{\star \star *}$ & $-.10^{\star \star *}$ & Supported \\
\hline $\begin{array}{l}\text { H5: Learn. Costs } \rightarrow \text { Intent. to use mobile payment (indirect } \\
\text { through fac. conditions) }\end{array}$ & n.a. & $-.17^{\star \star *}$ & $-.17^{\star * *}$ & Supported \\
\hline
\end{tabular}

Levels of significance: ${ }^{\star * *} p<.01$

\section{Discussion}

As mobile payment solutions are introduced by a variety of actors using highly different security technologies, distribution channels and interfaces, users are faced with a technology that lacks any de facto standards. This paper contends that, for technologies that lack de facto standards, learning costs play an important hidden role in explaining adoption intentions. Specifically, our results demonstrate the hidden role of learning costs in explaining adoption intentions, mediated through perceived functional value and facilitating conditions. Our findings are important not only for understanding mobile payment adoption, but also for acceptance of other technologies that lack de facto standards.

This research has pointed out three characteristics of mobile payment that may explain low adoption levels. First, due to the lack of de facto standards and the multitude of platforms and technologies, potential users face high uncertainty. Switching between technologies as platform and technology battles evolve incurs learning costs for users. We propose that the complexity and multitude of technologies and platforms makes potential users disproportionally concerned over learning costs, which in turn explains low adoption levels. Second, because a dominant standard is lacking, conditions are not fully in place yet to support mobile payment. For instance, NFC has only recently been proliferated into handsets, and industry players such as banks and payment service providers are adopting 'wait-and-see' strategies as technology battles between operators, handset manufacturers and over-the-top players are still unfolding [13]. Hence, we argue that the facilitating conditions in terms of organizational and technologies prerequisites may still be perceived as missing for consumers. Third, mobile payment functionality is 
very close to cash payment or debit card payment. The value from mobile payment is especially created for financial institutions (i.e. reduction of costs for circulating cash) and payment providers (i.e. opportunities to collect data on purchase behaviour). Therefore, we propose that the marginal value that is perceived from using mobile payment may explain low adoption levels.

Learning costs have generally been shown to negatively affect user intention [5], although prior studies in mobile payment produced mixed results [31]. In this paper, we examined the effect of learning costs on user intention, and to which extent this effect is mediated by perceived functional value and facilitating conditions. Indeed, the lower adoption rates of mobile payment have been reported in prior research [18] and stated to differ between countries and among diverse types of products or services which are bought using mobile payment systems [51]. The former can be explained by applying our reasoning that the marginal value is perceived differently by consumers when using mobile payment. A potential solution to increase perceived marginal value and, in turn, intention to use mobile payment services is to integrate them within social media networks [50] or atmospheric cues [64].

Our findings for mobile payments contribute to managerial practice and academic research. Since mobile payment services combine ubiquitous technologies and financial transactions, the intention to use mobile payments is determined by factors which may not affect the acceptance of other types of advanced mobile services. The present study shows that learning costs exist and have a negative impact on the intention to use mobile payments. That impact is not direct but indirect through two fully mediators: perceived functional value and facilitating conditions. Therefore, firms should be aware of this hidden impact of learning costs and work towards the reduction of those costs in order to increase the acceptance of mobile payment. Our results also show that learning costs are affected by facilitating conditions. Hence providers of mobile payment solutions (e.g. banks, operators, service providers) should promote fully developed and omnipresent services that can be used in everyday life and ensure that these services are less expensive for end users comparing to traditional payment methods.

Academically, research should, for instance, pull UTAUT over with regards to the effect of facilitating conditions on actual use of mobile payments, and focus, instead, on current research trend of studying facilitating conditions' impact on behavioural intention. Also, the fully mediating roles of facilitating conditions and perceived functional value in the link between learning costs and intention to use mobile payments shown here suggest that acceptance theories might include that indirect effect. Including the hidden, mediated effect of learning costs on user intentions may explain the lack of consensus in findings on learning costs in prior studies. Also, mobile payment services may be adopted differently depending on the type of product or service in question. For instance, mobile payment services are used mainly for transport in Scandinavian countries, while users in southern Europe usually pay food and clothes at stores with their mobile applications [51]. In summary, the analysis of mobile payment for specific types of products or services requires further analysis and research in the years to come.

\section{Limitations and Future Research Guidelines}

Our research was conducted with students in a major university. As previously stated, recent studies demonstrate that these respondents are always willing to try new features on their mobile phones and pay for them [16]. Therefore, this convenience sample seems appropriate for the purpose of our research. As the focus is on Learning costs, we argue that the choice to sample students is appropriate since they will evaluate Learning costs as less problematic than older or lower educated people. Hence, since we find, even in this sub-part of the population that is biased towards enjoying learning, that learning costs play a significant role, we expect that the results can be generalized to non-student populations as well. Although this could be considered as an adequate sample to test the intention to use mobile payments, it will be interesting to increase the external validity of our findings by carrying out the same study with another sample. Perhaps testing the same model in a different set of potential users.

Our research has analysed perceived functional value as an overall assessment but has not considered other dimensions, as we discussed in Section 2. Value has a functional aspect, as well as an emotional dimension. Functional value refers to the utility resulting from quality perception and performance expectation, while emotional value is defined as the utility derived from feelings or affective states that a product generates [62]. While these emotional values are not particularly relevant for mobile payment specifically, in general it might be assumed that higher levels of learning costs lead to frustrations which in turn negatively affect emotional values. Following previous studies, such as the one by [24], it will be interesting to explore a value-based adoption model of mobile payment where emotional value is related to enjoyment and functional value relates to usefulness.

Similarly, we have analysed users' intention to use mobile payment but have not considered what is the customer opinion of using this technology over time. Therefore, following other research guidelines in this filed it will be interesting to analysed the customer satisfaction of using mobile payment like other studies have done with similar technologies: SMS [14], social pages [9], mobile shopping [54] or online community [66].

Undoubtedly, firms are looking for a mobile payment solution that becomes a standard in the market. But, in order to obtain a successful platform to be adopted in the market, firms should balance the number of participants and functionalities that this platform offers to users [55]. Our findings may be generalized to technologies lacking de facto 
standards in general, but further research would provide more generalization power to other technologies with and without standards.

\section{Acknowledgements}

This work was supported by Fundación Cajamurcia. The authors want to thank editor and reviewers for their valuable comments.

\section{References}

[1] J. C. Anderson and D. W. Gerbing, Structural equation modelling in practice: A review and recommended twostep approach, Psychological Bulletin, vol. 103, no. 3, pp. 411-423, 1988.

[2] Y. A. Au and R. J. Kauffman, The economics of mobile payments: Understanding stakeholder issues for an emerging financial technology application, Electronic Commerce Research and Applications, vol. 7, no. 2, pp. 141-164, 2008.

[3] R. P. Bagozzi and Y. Yi, On the evaluation of structural equation models, Journal of the Academy of Marketing Science, vol. 16, no. 1, pp. 74-94, 1988.

[4] E. Bucherer, U. Eisert and O. Gassmann, Towards systematic business model innovation: lessons from product innovation management, Creativity and Innovation Management, vol. 21, no. 2, pp. 183-198, 2012.

[5] T. A. Burnham, J. K. Frels and V. Mahajan, Consumer switching costs: A tipology, antecedents, and consequences, Journal of the Academy of Marketing Science, vol. 31, no. 2, pp. 109-126, 2003.

[6] Y. Cao, Y. Lu, S. Gupta and S. Tang, The effects of differences between e-commerce and m-commerce on the consumers' usage transfer from online to mobile channel, International Journal of Mobile Communications, vol. 13, no. 1, pp. 51-70, 2015.

[7] L. D. Chen, A model of consumer acceptance of mobile payment, International Journal of Mobile Communications, vol. 6, no. 1, pp. 32-52, 2008.

[8] K. Y. Cheng and M. L. Chang, User acceptance of 'near field communication' mobile phone service: an investigation based on the 'unified theory of acceptance and use of technology' model, The service Industries Journal, vol. 33, no. 6, pp. 609-623, 2013.

[9] W. S. Chow and S. Shi, Investigating customers' satisfaction with brand pages in social networking sites, Journal of Computer Information Systems, vol. 55, no. 2, pp. 48-58, 2015.

[10] M. Cocosila and H. Trabelsi, An integrated value-risk investigation of contactless mobile payments adoption, Electronic Commerce Research and Applications, vol. 20, pp. 159-170, 2016.

[11] T. Dahlberg, J. Guo and J. Ondrus, A critical review of mobile payment research, Electronic Commerce Research and Applications, vol. 14, no. 5, pp. 265-284, 2015.

[12] T. Dahlberg, N. Mallat, J. Ondrus, and A. Zmijewska, Past, present and future of mobile payments research: A literature review, Electronic Commerce Research and Applications, vol. 7, no. 2, pp. 165-181, 2008.

[13] M. De Reuver and J. Ondrus, When technological superiority is not enough: The struggle to impose the SIM card as the NFC secure element for mobile payment platforms, Telecommunications Policy, vol. 41, no. 4, pp. 253-262, 2017.

[14] Z. Deng, Y. Lu, K. K. Wei, and J. Zhang, Understanding customer satisfaction and loyalty: An empirical study of mobile instant messages in China, International journal of information management, vol. 30, no. 4, pp. 289-300, 2010.

[15] S. G. Dewan and L. D. Chen, Mobile payment adoption in the USA: A crossindustry, cross-platform solution, Journal of Information Privacy \& Security, vol. 1, no. 2, pp. 4-28, 2005.

[16] T. Falk, W. H. Kunz, J. J. Schepers, and A. J. Mrozek, How mobile payment influences the overall store price image, Journal of Business Research, vol. 69, no. 7, pp. 2417-2423, 2016.

[17] C. Fornell and D. F. Larcker, Evaluating structural equation models with unobservable variables and measurement error, Journal of Marketing Research, vol. 18, no. 1, pp. 39-50, 1981.

[18] L. Gao and K. A. Waechter, Examining the role of initial trust in user adoption of mobile payment services: an empirical investigation, Information Systems Frontiers, vol. 19, no. 3, pp. 525-548, 2017.

[19] J. Henseler, C. M. Ringle and M. Sarstedt, A new criterion for assessing discriminant validity in variance-based structural equation modeling, Journal of the Academy of Marketing Science, vol. 43, no. 1, pp. 115-135, 2015.

[20] W.-M. Hur, J.-J. Yoo and T.-L. Chung, The consumption values and consumer innovativeness on convergence products, Industrial Management \& Data Systems, vol. 112, no. 5, pp. 688-706, 2012.

[21] M. A. Jones, D. L. Mothersbaugh and S. E. Beatty, Why customers stay: Measuring the underlying dimensions of services switching costs and managing their differential strategic outcomes, Journal of Business Research, vol. 55, no. 6, pp. 441-450, 2002.

[22] A. Juntunen, V. Tuunainen and S. Luukkainen, Critical business model issues in deploying NFC technology for mobile services: case mobile ticketing, International Journal of E-Services and mobile applications, vol. 4, no. 3, pp. 23-41, 2012.

[23] E. Kazan, C. Wee Tan and E. T. Lim, Towards a framework of digital platform competition: a comparative study of monopolistic \& federated mobile payment platforms, Journal of Theoretical and Applied Electronic Commerce Research, vol. 11, no. 3, pp. 50-64, 2016. 
[24] H. K. Kim, H. Chuan and S. Gupta, Value-based Adoption of Mobile Internet: An empirical investigation, Decision Support Systems, vol. 43, no. 2, pp. 111-126, 2007.

[25] M. Kleijnen, K. Ruyter and M. Wetzels, An assessment of value creation in mobile service delivery and the moderating role of time consciousness, Journal of Reatiling, vol. 83, no. 1, pp. 33-46, 2007.

[26] P. Klemperer, Markets with consumer switching costs, The Quarterly Journal of Economics, vol. 102, no. 2, pp. 375-394, 1987

[27] C. Kohli, Signaling new product introductions: A framework explaining the timing of preannouncements, Journal of Business Research, vol. 46, no. 1, pp. 45-56, 1999.

[28] A. Köster, C. Matt and T. Hess, Carefully choose your (payment) partner: How payment provider reputation influences m-commerce transactions, Electronic Commerce Research and Applications, vol. 15, no. 1, pp. 2637, 2016.

[29] B. Kousaridas, G. Parissis and T. Apostolopoulos, An open financial services architecture based on the use of intelligent mobile devices, Electronic Commerce Research and Applications, vol. 7, no. 2, pp. 232-246, 2008.

[30] Y.-K. Lee, J.-H. Park, N. Chung, and A. Blakeney, A unified perspective on the factors influencing usage intention toward mobile financial services, Journal of Business Research, vol. 65, no. 11, pp. 1590-1599, 2012.

[31] L. Y. Leong, T. S. Hew, G. W. H. Tan, and K. B. Ooi, Predicting the determinants of the NFC-enabled mobile credit card acceptance: a neural networks approach, Expert Systems with Applications, vol. 40, no. 14, pp. 5604-5620, 2013

[32] F. Lieabana-Cabanillas, F. Muñoz-Leiva and J. Sanchez-Fernandez, The impact of risk on the technological acceptance of mobile payment services, Global Business Perspectives, vol. 1, no. 4, pp. 309-328, 2013.

[33] M. K. Lindell and D. J. Whitney, Accounting for common method variance in cross-sectional research designs, Journal of Applied Psychology, vol. 86, no. 1, pp. 1111-1125, 2001.

[34] J. Liu, R. J. Kauffman and D. Ma, Competition, cooperation, and regulation: Understanding the evolution of the mobile payments technology ecosystem, Electronic Commerce Research and Applications, vol. 14, no. 5, pp. 372-391, 2015

[35] Y. Lu, S. Yang, P. Y. Chau and Y. Cao, Dynamics between the trust transfer process and intention to use mobile payment services: A cross-environment perspective, Information \& Management, vol. 48, no. 8, pp. 393403, 2011.

[36] N. Malhotra, S. Kim and A. Patil, Common method variance in IS research: A comparison of alternative approaches and a reanalysis of past research, Management Science, vol. 52, no. 12, pp. 1865-1883, 2006.

[37] N. Mallat, M. Rossi, V. Tuunainen and A. Öörni, The impact of use context on mobile services acceptance: The case of mobile ticketing, Information \& Management, vol. 46, no. 3, pp. 190-195, 2009.

[38] E. Mao, M. Srite, J. Thatcher, and O. Yaprak, A research model for mobile phone service behaviors: Empirical validation in the U.S. and Turkey, Journal of Global Information Technology Management, vol. 8, no. 4, pp. 728, 2005.

[39] M. Miao and K. Jayakar, Mobile payments in Japan, South Korea and China: Cross-border convergence or divergence of business models?, Telecommunications Policy, vol. 40, no. 2, pp. 182-196, 2016.

[40] S. Okazaki, F. Molina and M. Hirose, Mobile advertising avoidance: exploring the role of ubiquity, Electronic Markets, vol. 22, no. 3, pp. 169-183, 2012.

[41] P. Ozcan and F. M. Santos, The market that never was: Turf wars and failed alliances in mobile payments, Strategic Management Journal, vol. 36, no. 10, pp. 1486-1512, 2015.

[42] M. Pagani, Determinants of adoption of third generation mobile multimedia services, Journal of Interactive Marketing, 2004

[43] Y. Park and Y. Koo, An empirical analysis of switching cost in the smartphone market in South Korea, Telecommunications Policy, vol. 40, no. 4, pp. 307-318, 2016.

[44] R. Peng, L. Xiong and Z. Yang, Exploring tourist adoption of tourism mobile payment: An empirical analysis, Journal of Theoretical and Applied Electronic Commerce Research, vol. 7, no. 1, pp. 21-33, 2012.

[45] P. M. Podsakoff, S. B. Mackenzie, J. Lee, and N. P. Podsakoff, Common method biases in behavioral research: A critical review of the literature and recommended remedies, Journal of Applied Psychology, vol. 20, no. 5, pp. 879-903, 2003

[46] K. Pousttchi, A modeling approach and reference models for the analysis of mobile payment use cases, Electronic Commerce Research and Applications, vol. 7, no. 2, pp. 182-201, 2008.

[47] K. J. Preacher and A. F. Hayes, Asymptotic and resampling strategies for assesing and comparing indirect effects in multiple mediator models, Behavior Research Methods, vol. 40, no. 3, pp. 879-891, 2008.

[48] M. Pura, Linking perceived value and loyalty in location-based mobile services, Managing Service Quality: An International Journal, vol. 15, no. 6, pp. 509-538, 2005.

[49] H. Qasim and E. Abu-Shanab, Drivers of mobile payment acceptance: The impact of network externalities, Information Systems Frontiers, vol. 18, no. 5, pp. 1021-1034, 2016.

[50] Y. Qu, W. Rong, H. Chen, Y. Ouyang, and Z. Xiong, Influencing factor analysis for a social network web based payment service in china, Journal of Theoretical and Applied Electronic Commerce Research, vol. 13, no. 3, pp. 99-103, 2018.

[51] V. Saprikis, A. Markos and T. Zarmpou, Mobile shopping consumers' behavior: an exploratory study and review, Journal of Theoretical and Applied Electronic Commerce Research, vol. 13, no. 1, pp. 71-90, 2018.

[52] V. Senić and V. Marinković, Examining the effect of different components of customer value on attitudinal loyalty and behavioral intentions, International Journal of Quality and Service Sciences, vol. 6, no. 2/3, pp. 134142, 2014. 
[53] A. Shaikh, P. Hanafizadeh and H. Karjaluoto, Mobile banking and Ppyment system: A conceptual standpoint, International Journal of E-Business Research (IJEBR), vol. 13, no. 2, pp. 14-27, 2017.

[54] D. Shang, D. Shang, W. Wu, and W. Wu, Understanding mobile shopping consumers' continuance intention, Industrial Management \& Data Systems, vol. 117, no. 1, pp. 213-227, 2017.

[55] K. S. Staykova and J. Damsgaard, Adoption of mobile payment platforms: Managing reach and range, Journal of Theoretical and Applied Electronic Commerce Research, vol. 11, no. 3, pp. 65-84, 2016.

[56] Y. Sun, N. Wang, X. Guo, and Z. Peng, Understanding the acceptance of mobile health services: A comparison and integration of alternative models, Journal of Electronic Commerce Research, vol. 14, no. 2, p. 183, 2013.

[57] J. C. Sweeney and G. N. Soutar, Consumer perceived value: The development of a multiple item scale, Journal of Retailing, vol. 77, no. 2, pp. 203-220, 2001.

[58] Y. Taran, H. Boer and P. Lindgren, A business model innovation typology, Decisions Sciences, vol. 46, no. 2 , pp. 301-331, 2015.

[59] E. Taylor, Mobile payment technologies in retail: A review of potential benefits and risks, International Journal of Retail \& Distribution Management, vol. 44, no. 2, pp. 159-177, 2016.

[60] A.-C. Teo, G. W.-H. Tan, K.-B. Ooi, T.-S. Hew, and K.-T. Yew, The effects of convenience and speed in mpayment, Industrial Management \& Data Systems, vol. 115, no. 2, pp. 311-331, 2015.

[61] R. Thakur, Customer adoption of mobile payment services by professionals across two cities in India: An empirical study using modified technology acceptance model, Business Perspectives and Research, vol. 1, no. 2, pp. 17-30, 2013.

[62] O. Turel, A. Serenko and N. Bontis, User acceptance of wireless short messaging services: Deconstructing perceived value, Information \& Management, vol. 44, no. 1, pp. 63-73, 2007.

[63] V. Venkatesh, M. Morris, G. Davis, and F. D. Davis, User acceptance of information technology: Toward a unified view, MIS Quarterly, vol. 27, no. 3, pp. 425-478, 2003.

[64] T. S. Vijay, S. Prashar and V. Sahay, The influence of online shopping value and web atmospheric cues on eloyalty: Mediating role of e-satisfaction, Journal of Theoretical and Applied Electronic Commerce Research, vol. 14, no. 1, pp. 1-15, 2019.

[65] A. M. Voorhees, M. K. Brady, R. Calantone, and E. Ramirez, Discriminant validity testing in marketing: An analysis, causes for concern, and proposed remedies, Journal of the Academy of Marketing Science, vol. 44, no. 1, pp. 119-134, 2016

[66] S.-C. Wang, E. Sy and K. Fang, The post-adoption behavior of online knowledge community: Decomposing customer value, Journal of Computer Information Systems, vol. 51, no. 2, pp. 60-70, 2010.

[67] A. M. Weiss and J. B. Heide, The nature of organizational search in high technology markets, Journal of Marketing Research, vol. 30, no. 2, pp. 220-233, 1993.

[68] C.-H. Wong, G. Wei-Han, K.-B. Ooi, and B. Lin, Mobile shopping: the next frontier of the shopping industry? An emerging market perspective, International Journal of Mobile Communications, vol. 13, no. 1, pp. 92-112, 2015.

[69] K. Yang and J. C. Forney, The moderating role of consumer technology anxiety in mobile shopping adoption: Differential effects of facilitating conditions and social influences, Journal of Electronic Commerce Research, vol. 14, no. 4, p. 334, 2013.

[70] Y. Yang, Y. Liu, H. Li, and B. Yu, Understanding perceived risks in mobile payment acceptance, Industrial Management \& Data Systems, vol. 11, no. 2, pp. 1-15, 2015.

[71] V. A. Zeithaml, Consumer perceptions of price, quality and value: A means-end model and synthesis of evidence, Journal of Marketing, vol. 52, no. 2, pp. 2-22, 1988.

[72] X. Zhao, S. Deng and Y. Zhou, The impact of reference effects on online purchase intention of agricultural products: The moderating role of consumers' food safety consciousness, Internet Research, vol. 27, no. 2, pp. 233-255, 2017.

[73] T. Zhou, An empirical examination of continuance intention of mobile payment services, Decision Support Systems, vol. 54, no. 2, pp. 1085-1091, 2013. 